\title{
ANÁLISE CRÍTICA DO DISCURSO: UM MARCO TEÓRICO- METODOLÓGICO PARA PESQUISAS EM EDUCAÇÃO EM CIÊNCIAS
}

\author{
CRITICAL DISCOURSE ANALYSIS: A THEORETICAL- \\ METHODOLOGICAL FRAMEWORK FOR RESEARCH IN SCIENCE \\ EDUCATION
}

\author{
Edileuza Dias de Queiroz ${ }^{1}$, Laísa Freire ${ }^{2}$ \\ ${ }^{1}$ Universidade Federal do Rio de Janeiro - Programa de Pós-graduação em Educação em Ciências e \\ Saúde e Universidade Federal Rural do Rio de Janeiro, Departamento de Educação e Sociedade \\ edileuzaqueiroz@gmail.com \\ ${ }^{2}$ Universidade Federal do Rio de Janeiro, Instituto de Biologia, Departamento de Ecologia, Laboratório \\ de Limnologia, Programa de Pós-graduação em Educação em Ciências e Saúde \\ laisa@biologia.ufrj.br
}

\section{Resumo}

Este ensaio teórico pretende contribuir para o embasamento teórico-metodológico de pesquisas na área de educação em ciências a partir dos estudos da linguagem referenciados pela Análise Crítica do Discurso (ACD). Consideramos a ACD, desenvolvida por Norman Fairclough, um referencial com condições de atender às demandas de pesquisas em educação em ciências envolvendo aspectos sociais, suas relações de poder e questões linguísticas. Para a $\mathrm{ACD}$, práticas sociais são discursivamente moldadas e constituídas, o discurso que é linguisticamente analisável, constitui elemento chave para esta interpretação. A ACD relaciona-se com outras teorias e métodos sociais, engajando-se não apenas de maneira interdisciplinar, mas transdisciplinar, entendendo que o diálogo entre disciplinas e arcabouços pode levar ao desenvolvimento das mesmas por meio de um processo de cada uma internamente se apropriar da lógica da outra como recurso para seu próprio desenvolvimento.

Palavras-chave: Análise Crítica do Discurso; referencial teórico-metodológico; educação em ciências

\begin{abstract}
This study intends to contribute to the theoretical and methodological basis of research in Science Education (SE) using the approach of Critical Discourse Analysis (CDA). We consider CDA, developed by Norman Fairclough, a critical approach to address demands of research in SE. This theory discuss linguistic issues involving social aspects, as it constitutes an important theoretical and methodological framework to the analysis of texts. For CDA, social practices are discursively shaped, the intrinsic properties of discourse, which are linguistically analyzable, constitute a key element of their interpretation. CDA is related to other theories and social methods in a transdisciplinary way. The dialogue between two disciplines and frameworks may lead to a development of both by a process of each internally appropriating the logic of the other as a resource for its own development.
\end{abstract}




\section{Ensino, Saúde e Ambiente - V 7 (1), Edição Especial, maio de 2014}

Keywords: Critical Discourse Analysis, theoretical-methodological framework, Science Education

\section{Introdução}

Este estudo é parte de uma tese de doutorado desenvolvida no Programa de Pósgraduação em Educação em Ciências, que busca discutir questões da formação inicial docente nas ciências por meio dos estudos da linguagem. Interessa-nos entender os movimentos de disputas discursivas na construção de hegemonias do discurso quando se discute a inserção curricular da educação ambiental na formação do licenciado em ciências biológicas. Deste modo, no presente estudo, buscamos fortalecer a discussão teórica do quadro teórico-metodológico da Análise Crítica do Discurso (ACD) de modo a pensar em contribuições paras as pesquisas em educação em ciências.

Bakhtin (1992), busca na linguagem a chave da compreensão para as principais questões epistemológicas que perpassam as ciências humanas e sociais. A linguagem é um elemento básico, fundamental na vida social, é parte da sociedade. Segundo Resende e Ramalho (2011), a perspectiva funcionalista da linguagem permite entender de que modo os sistemas linguísticos funcionam na representação de eventos, na construção de relações sociais, na estruturação, reafirmação e contestação de hegemonia no discurso.

Como processo social, a linguagem envolve o discurso, sendo este uma forma de ação e intervenção no mundo, pois é através dele que os indivíduos constroem sua realidade social, agem no mundo em condições histórico-sociais e nas relações de poder nas quais operam (FAIRCLOUGH, 2001). Segundo o autor, o Discurso não é apenas prática de representação do mundo, mas também prática de significação no mundo, construindo o mundo em significado. Desta forma, afirma o autor, o Discurso contribui para a construção de identidades sociais, relações sociais entre as pessoas e sistemas de conhecimento e crenças.

Através de revisão de literatura relacionada aos estudos do discurso de Norman Fairclough, entendemos que por meio da ACD, é possível oferecer novas formas de entender a realidade, buscando-se desvelar ideologias e valores vigentes nos discursos que circulam na sociedade. É fato que todos os indivíduos vivem imersos em sistemas socioculturais estruturados a partir de códigos simbólicos e de normas, que de alguma forma regulam as práticas sociais. Tais práticas sociais são conformadas e conformam Discursos que caracterizam modos de agir, representar e identificar. 
Para uma construção teórico-metodológica em pesquisas humanas, especialmente na educação em ciências, a ACD pode contribuir de forma que possamos entender movimentos de ruptura de estruturas aparentemente cristalizadas na vida social a partir das relações entre forma e função da linguagem, pois é tarefa da ACD a construção de um corpo teórico integrado, a partir do qual seja possível desenvolver uma descrição, explicação e interpretação dos modos como os discursos dominantes influenciam o conhecimento, os saberes, as atitudes e também as ideologias socialmente compartilhadas. Neste sentido, a ACD "é motivada pelo objetivo de prover bases para um questionamento crítico da vida social em termos políticos e morais, ou seja, em termos de justiça social e de poder" (FAIRCLOUGH, 2003, apud, Resende e Ramalho, 2004, p.190).

Embora a ACD não tenha em sua gênese preocupações com o campo da educação, temos observado autores (ROGERS, 2004; MARTINS et al 2008; SANTOS, 2010; FREIRE 2012) direcionam suas pesquisas na interface entre a ACD e a educação. Este ponto é central para a nossa abordagem, pois nosso trabalho tem o foco no campo educacional. Especificamente Rogers (2004) em seu trabalho argumenta que a ACD contribui ao entendimento da aprendizagem, como objetivo principal da pesquisa educacional, de dois modos. O primeiro relaciona-se ao fato da análise ser crítica, o que permite o problematizar criticamente os processos de aprendizagem, considerando suas relações sociohistóricas. O segundo refere-se ao processo da própria $\mathrm{ACD}$ no qual pesquisadores e participantes são moldados oferecendo possibilidades não apenas para a crítica, mas também para a transformação social que surge da crítica.

É a partir desses pressupostos que consideramos a ACD como uma opção que favorece às pesquisas em ciências humanas, pois, segundo Amorim (2007, p. 12):

\footnotetext{
Nas ciências humanas conjugam-se as dimensões ética e estética para dar origem a uma outra dimensão que é a epistemológica. Desse modo, a produção de conhecimentos e o texto em que se dá esse conhecimento são uma arena onde se confrontam múltiplos discursos. (...) entre o discurso do sujeito a ser analisado e conhecimento e discurso do próprio pesquisador que pretende analisar e conhecer, uma vasta gama de significados conflituais e mesmo parodoxais vai emergir.
}

Contudo, de acordo com o referencial da $\mathrm{ACD}$, tais significados construídos, não são conflituais ou paradoxais, e sim constituintes da linguagem e de seus processos intertextuais. 


\section{Breve histórico da Análise Crítica do Discurso}

A partir da década dos anos 70 do século $\mathrm{XX}^{1}$, desenvolveu-se uma forma de análise do discurso que identificava o papel da linguagem na estruturação das relações de poder na sociedade, a análise crítica do discurso (ACD) ${ }^{2}$ (FAIRCLOUGH, 2001). Gouveia (2001) entende quatro grandes momentos históricos centrais para o desenvolvimento da ACD. O primeiro refere-se ao surgimento da linguística crítica em oposição às teorias linguísticas dominantes à época, que consideravam o significado descolado do estilo ou expressão e a separação entre estrutura e signos linguísticos. Por outro lado, a linguística crítica defende que os grupos e as relações sociais influenciam o comportamento linguístico e não-linguístico dos sujeitos, incluindo a sua atividade cognitiva. Em 1985, configura-se um segundo momento, no qual Fairclough se afasta relativamente do projeto inicial da linguística crítica. A publicação Critical and Descriptive Goals in Discourse Analysis marca este momento. O terceiro marco para o estabelecimento da ACD foi a publicação da revista "Discourse and Society", em 1990, dirigida por Teun Van Dijk, marcando, segundo Gouveia (2001), a ACD como uma área de investigação e especialização acadêmicas. O ano de 1996 marcou um quarto momento de cosnolidação, pois neste ano foi publicada uma coleção de livros intitulada Critical Discourse Analysis dirigida por Norman Fairclough.

Esta área, longe de ser homogênea reúne pesquisadores diferentes enfoques de estudo $^{3}$. São nomes expoentes: Teun van Dijk, Norman Fairclough, Gunter Kress, Theo van Leeuven e Ruth Wodak. Dessa forma, esse tipo de marco teórico-metodológico surgiu com um grupo de estudiosos, de caráter internacional e heterogêneo. Santos, (2010) recupera estas diferentes abordagens para caracterizar a ACD: Meyer (2003) entende que Norman Fairclough tem sua abordagem a partir da linguística multifuncional de Halliday (1978) utilizando também o conceito de ordem de discurso

\footnotetext{
${ }^{1}$ Cabe aqui ressaltar que, na década de 60, alguns movimentos consolidavam estudos sobre a importância das mudanças sociais como perspectiva de análise. Na Grã-Bretanha, por exemplo, um grupo de linguistas desenvolveu uma "linguística crítica", articulando as teorias e os métodos de análise textual da "linguística sistêmica", de Halliday, com teorias sobre ideologias. Já na França, Pêcheux e Jean Dubois desenvolveram uma abordagem da análise de discurso, baseados no trabalho do linguista Zellig Harris e a reelaboração da teoria marxista sobre a ideologia, feita por Althusser, que ficou conhecida como Análise do Discurso Francesa.

${ }^{2}$ No presente trabalho apenas consideramos alguns aspectos gerais para a reconstrução da configuração histórica da ACD. Para estudos mais detalhados sobre o surgimento da ACD consultar: Gouveia (2001); Nascimento (2010) e Melo (2011).

${ }^{3}$ Por isso, é importante mencionar as publicações: "Language and power", de Norman Fairclough, em 1989; "Language, power and ideology", de Ruth Wodak, em 1989; e a obra de Teun van Dijk sobre racismo, "Prejudice in discourse", em 1984.
} 
de Foucault enquanto que Ruth Wodak e Teun Van Dijk introduzem um nível sócio cognitivo nas análises. Contudo, Van Dijk (2002, p. 20) expõe, diferentemente de Meyer (2003) como entende algumas das diferenças, situando os autores:

\begin{abstract}
Norman Fairclough em uma perspectiva que tem suas raízes no neomarxismo, se interessa mais pelas estruturas globais de poder, como a globalização. Ruth Wodak agrega uma dimensão histórica, por exemplo, em seus estudos sobre anti-semitismo, instituições e gênero. Luisa Martín Rojo em Madrid trabalha sobre racismo, gênero e outros temas a partir de uma perspectiva foucaultiana.
\end{abstract}

Este autor, ainda distingue a sua própria perspectiva de trabalho, e a descreve como mais centrada no que concerne à integração da dimensão sócio cognitiva nas pesquisas sobre a reprodução da dominação.

\title{
Aprofundando a abordagem faircloughiana da Análise Crítica do Discurso
}

Segundo Resende e Ramalho (2011), foi através do livro "Language and Power", publicado em 1989, que a abordagem faircloughiana da ACD começou a se constituir como uma ciência crítica sobre a linguagem. Para as autoras a obra tinha como objetivo contribuir tanto para a conscientização sobre os efeitos sociais de textos quanto para mudanças sociais que superassem relações assimétricas de poder, parcialmente sustentadas pelo discurso. Contudo, ao longo de seus trabalhos a ACD experimenta uma mudança de ênfase do aspecto linguístico para o aspecto sociológico, tanto do ponto de vista teórico quanto analítico. O trabalho de Fairclough (1992), em sua primeira fase, é baseado na linguística Sistêmica Funcional de Halliday (1991), teoria que considera a linguagem na forma como ela é configurada pelas funções sociais que deve atender. Halliday (1991) apresenta e descreve três macrofunções da linguagem no processo de comunicação, a saber: ideacional, interpessoal e textual. Contudo, Fairclough, segundo Resende (2009), as redefine para funções ideacional, identitária, relacional e textual (1992) e para significados representacionais, identificacionais e acionais (na formulação de 1999). Para Resende e Ramalho, (2004, p 190) a nova formulação tem o objetivo de "refletir sobre a mudança social contemporânea, sobre as mudanças globais de larga escala e sobre a possibilidade de práticas emancipatórias em estruturas cristalizadas na vida social.” Neste enquadre, Resende e Ramalho (2004, p 190) afirmam que:

a ADC assentada como reflexão sobre o discurso é localizada no contexto da Modernidade Tardia. O seu enquadramento dá-se: (i) numa visão científica de crítica social; (ii) no campo da pesquisa social crítica sobre a modernidade tardia; e (iii) na teoria e na análise linguística e semiótica. 
Nesta abordagem, a localização teórica da ACD está em compreender o discurso como um momento de prática social, sabendo que todas as práticas sociais incluem os seguintes elementos: atividade produtiva, meios de produção, relações sociais, identidades sociais, valores culturais, consciência e semioses. Esses elementos se acham relacionados dialeticamente, isto é, não são elementos discretos, embora sejam diferentes.

Segundo Fairclough (2001, p. 275), a prática da ACD não deve seguir um esquema predeterminado, rígido, "pois não há procedimento fixo para se fazer análise de discurso; as pessoas abordam-na de diferentes maneiras, de acordo com a natureza específica do projeto e conforme suas respectivas visões do discurso". Apesar disso, ele, em diferentes publicações, sugere diretrizes para construção dos dados, das análises e dos resultados, ressaltando que, o ideal é que o analista deva realizar um trabalho interdisciplinar. Fairclough e Chouliaraki (1999) criam uma agenda de pesquisa para a ACD baseada em pares dialéticos como pares de termos contraditórios no discurso da modernidade tardia. Estes pares são: colonização/apropriação; globalização/localização; reflexividade/ideologia e identidade/diferença.

\section{O percurso metodológico ancorado na ACD}

Segundo Melo (2011), o objetivo metodológico do analista crítico é investigar traços e pistas a fim de tornar visíveis as relações existentes entre a linguagem e outras práticas sociais, que são dadas como naturais. Segundo, Resende (2009) a vantagem de uma análise do discurso textualmente orientada é que a mesma permite e fundamenta uma análise social a partir dos dados linguísticos sustentando a crítica explanatória. Ainda acrescenta, "por meio de análises discursivas críticas, é possível identificar conexões entre escolhas linguísticas de atores sociais ou grupos e os contextos sociais mais amplos nos quais os textos analisados são formulados." (RESENDE, 2009). Neste sentido, a proposta da ACD é desconstruir os significados implícitos ou ocultos que estão presentes nos textos, e com isso expor elementos indiciais reprodutores da organização social, que privilegia certos grupos e indivíduos em detrimento de outros, por meio de formas institucionalizadas de ver e avaliar o mundo (ideologias) ou preservação de poderes (hegemonia) de grupos dominantes (MELO, 2011).

Para realizar uma estrutura analítica da ACD, Chouliaraki e Fairclough (1999) 


\section{Ensino, Saúde e Ambiente - V 7 (1), Edição Especial, maio de 2014}

colocam algumas diretrizes apresentadas a seguir baseadas no realismo crítico de Bhaskar:

1) Perceber um problema em alguma parte da vida social e identificar seu aspecto semiótico;

2) Identificar os obstáculos para que esse problema seja resolvido, pela:

a) Análise da conjuntura - especificação da configuração das práticas nas quais o discurso é localizado;

b) Análise da prática particulares ou práticas e suas relações com outros elementos (atividade material, processos mentais, relações sociais) dentro das práticas particulares em questão;

c) Análise do discurso:

i) Análise estrutural: a ordem de discurso;

ii) Análise interacional;

a. Análise interdiscursiva;

b. Análise linguística e semiótica.

3) Discutir a função do problema na prática considerando se e como o aspecto problemático do discurso em foco tem uma função dentro da prática;

4) Identificar maneiras possíveis para superar os obstáculos;

5) Refletir criticamente sobre os itens 3 e 4 (acima citados).

Após apresentar o esquema acima, Fairclough vai explicando cada um dos itens, que ele denomina de estágios - como segue abaixo, de forma sucinta - . Segundo o autor, esse modelo de análise é a combinação de elementos relacionais com elementos dialéticos, combinando uma apreciação negativa, no diagnóstico do problema, com uma apreciação positiva, na identificação das possibilidades até então inexistentes para a sua resolução.

O estágio 1 mostra como essa abordagem da ACD é baseada em problemas, e há a necessidade de perguntar: um problema para quem? O autor ressalta que a ACD é uma forma de ciência social crítica, projetada para mostrar problemas enfrentados pelas pessoas em razão das formas particulares de vida social, fornecendo recursos para que se chegue a uma solução. Complementa que os assuntos problemáticos e que requerem mudanças são controversos e contestáveis, e a ACD estará envolvida em debates e controvérsias sociais quando enfatizar certas características da vida social como problema. 
O estágio 2 aborda o diagnóstico do problema de uma forma indireta, questionando quais são os obstáculos a serem superados. O diagnóstico considera a maneira pela qual as práticas sociais se inter-relacionam, o modo de relação da semiose com outros elementos de práticas sociais e com características de discurso em si.

O estágio 3 é uma forma indireta de ligar as coisas como realmente são com o que elas devem ser. Fairclough exemplifica com o problema da ideologia: o discurso é ideológico na medida em que contribui para a manutenção de relações particulares de poder e dominação.

O estágio 4 transforma a apreciação crítica negativa em positiva, através da identificação das possibilidades de mudanças ainda não concebidas, ou concebidas parcialmente. Esta fase pode estar voltada para apontar contradições, lacunas, deficiências dentro dos aspectos considerados dominantes da ordem social, ou ainda mostrar diferenças e resistências.

O último estágio, 5, é o momento em que a análise se torna reflexiva, questionando sua eficácia como apreciação crítica, sua contribuição para aprofundamentos teórico-metodológicos de trabalhos acadêmicos e mudança social.

\section{As contribuições da ACD para as pesquisas em Ensino de Ciências}

Na sociedade contemporânea um dos grandes desafios é produzir conhecimento, e não apenas transmitir, pois isto representa uma educação bancária (FREIRE, 2005), que não leva o educando à construção do conhecimento. A educação científica, segundo Moura (2012), deve fazer parte da formação do cidadão, para que ele possa compreender, opinar e tomar decisões baseadas no entendimento sobre o progresso científico e os riscos e conflitos de interesses que nele estão inseridos. Para Santos (2007), a educação científica é um conceito amplo, que depende do contexto histórico no qual ela é proposta, depende ainda de pressupostos ideológicos e filosóficos, tendo em vista que a ciência engloba diferentes atores sociais.

Neste sentido, segundo Santos (2007), o objetivo central do ensino de ciências é promover a educação científica e tecnológica, auxiliando o aluno na construção de conhecimentos, habilidades e valores necessários às tomadas de decisões responsáveis sobre questões de ciência e tecnologia e atuar na solução de tais questões. A questão da linguagem no ensino de ciências deve ser considerada questão central, Martins (2006, p. 120) afirma que "a linguagem é mais do que um conjunto de recursos simbólicos de expressão e comunicação: é instância constitutiva de identidades, de relações entre 
sujeitos, e de relações entre sujeitos, instituições e conhecimento". Halliday (1993, apud Santos, 2007), afirmam que a linguagem científica apresenta características próprias que a distingue da linguagem cotidiana. Mortimer (1998, apud Santos, op cit), demonstra que a linguagem científica é um gênero de discurso que foi construído socialmente pelos cientistas em sua prática, enquanto a linguagem científica é estrutural e aparentemente descontextualizada, sem narrador, nominalizando processos, a linguagem cotidiana é linear, automática, dinâmica, geralmente produzida por um narrador em uma sequência de eventos.

Reafirmamos aqui a importância da ACD enquanto ferramenta teóricometodológica, que permite problematizar a linguagem, as questões do poder da ciência, a linguagem da autoridade, os discursos da ciência. E assim, nos permite compreender melhor os limites do ensino de ciências e trabalhar para a superação destes limites, tendo em vista as transformações sociais.

\section{Considerações finais}

Consideramos a ACD o "fio condutor" que pode dá suporte teóricometodológico para o alcance dos objetivos de pesquisas, especialmente as de cunho social. De acordo com Magalhães (2005), este referencial estuda textos e eventos em diversas práticas sociais, propondo uma teoria e um método para descrever, interpretar e explicar a linguagem no contexto sociohistórico. Esta autora afirma que a ACD desenvolveu o estudo da linguagem como prática social, com vistas à investigação e transformações na vida social contemporânea.

A ACD tem uma relação dialógica com outras teorias e métodos sociais, engajando-se não apenas de maneira interdisciplinar, mas transdisciplinar, entendendo que o diálogo entre disciplinas e arcabouços pode levar ao desenvolvimento das mesmas por meio de um processo de cada uma internamente apropriarem-se da lógica da outra como recurso para seu próprio desenvolvimento. Concluímos que, pelo fato da ferramenta teórico-metodológica aqui defendida, acreditamos que a contribuição da ACD para a pesquisa em educação de ciências situa-se no sentido de gerar caminhos para entender processos de mudança social em diferentes escalas.

\section{Referências bibliográficas}

AMORIM, M. A contribuição de Mikhail Bakhtin: a tripla articulação ética, estética e epistemológica. In: Ciências humanas e pesquisa: leitura de Mikhail 
Bakhtin.FREITAS, M.T.; SOUZA, S.J.; KRAMER, S. (orgs.). - 2.ed. São Paulo, Cortez, 2007.

BAKHTIN, M. Marxismo e filosofia da linguagem. 6. ed. São Paulo: Hucitec, 1992.

FAIRCLOUGH, N. Discurso e mudança social. Brasília: Universidade de Brasília, 2001.

FREIRE, L.M.. et al. Discursos da Educação Ambiental produzidos por professores em formação continuada. In: Revista Brasileira de Pesquisa em Educação em Ciências, v. 12, n. 2, 2012.

FREIRE, P. Pedagogia do oprimido. Rio de Janeiro: Paz e Terra, 2005.

FREIRE, L.M. ; BOZELLI, R. L. ; ESPINET, M. ; MARTINS, I. . Discursos de Educação Ambiental produzidos por professores em formação continuada. Revista Brasileira de Pesquisa em Educação em Ciências, v. 12, p. 93-110, 2012.

GOUVEIA, C.A.M. Análise Crítica do Discurso: Enquadramento Histórico. In MATEUS, Maria Helena \& Clara Nunes Correia (orgs.): Saberes no Tempo: Homenagem a Maria Henriqueta Costa Campos. Lisboa: Edições Colibri: 335-351. 2001.

HALLIDAY, M.A.K. Language and Social Semiotics. London: Edward Arnold, 1978. MAGALHÃES, I. Introdução: A Análise de Discurso Crítica. D.E.L.T.A., v.21:

Especial, p. 1-9, 2005.

MARTINS, I. Analisando livros didáticos na perspectiva dos estudos do discurso: compartilhando reflexões e sugerindo uma agenda para a pesquisa. In: Pro-Posições, v. 17, n.1 (49), 2006.

MARTINS, I. ; OLINISKY, M.J ; ABREU, T. B. ; FREIRE, L.M. . Contribuições da análise crítica do discurso para uma reflexão sobre questões do campo da Educação Ambiental: olhares de educadores em ciências. Pesquisa em Educação Ambiental (Online), v. 3, p. 129-154, 2008.

MELO, I.F. Análise Crítica do Discurso como método em pesquisa social científica. In: Revista Linha d'Água, n. 25, v.2, p. 307-329, 2012.

Análise Crítica do Discurso: modelo de análise linguística e intervenção social. In: Revista Estudos Linguísticos, São Paulo, v. 40, n.3, p. 1335-1346, 2011.

MEYER, M. Entre la teoria, el método y la política: la ubicación de los enfoques relacionados com el ACD. En: WODAK, R.; (orgs). Métodos de análisis crítico del discurso. Barcelona: Gedisa, p. 35-59, 2003.

MOURA, M,A. (Org.). Educação científica e cidadania: abordagens teóricas e metodológicas para a formação de pesquisadores juvenis. Belo Horizonte:

UFMG/PROEX, 2012. 
Ensino, Saúde e Ambiente - V 7 (1), Edição Especial, maio de 2014

RESENDE, V.M. Análise de discurso crítica e realismo crítico: implicações interdisciplinares, Campinas, SP: Pontes Editores, 2009.

RESENDE, V.M. \& RAMALHO, V. Análise de Discurso Crítica. $2^{\mathrm{a}}$ edição. São Paulo: Contexto, 2011.

RESENDE, V. M.; RAMALHO, V. C. S., Análise de Discurso Crítica, do modelo tridimensional à articulação entre práticas: implicações teórico-metodológicas, Linguagem em (dis)curso, v. 5, n. 2, 2004.

ROGERS, R. An introduction to Critical Discourse Analysis in Education. Lawrence Erlbaum. 2004.

SANTOS, L.M.F. Discursos de Educação Ambiental na Formação de

Educadores(as) Ambientais: uma abordagem a partir da análise crítica do discurso. Tese de Doutorado. UFRJ/NUTES, Rio de Janeiro, 2010.

SANTOS, W.L.P. Educação científica na perspectiva de letramento como prática social: funções, princípios e desafios. In: Revista Brasileira de Educação, v. 12, n, 36, 2007. 